\title{
Article \\ Effect of Water Leaching on Photodegraded Scots Pine and Spruce Timbers Monitored by FTIR Spectroscopy
}

\author{
Edina Preklet ${ }^{1}$, László Tolvaj ${ }^{1}$, Eszter Visi-Rajczi ${ }^{2}$ and Tamás Hofmann ${ }^{2, *}$ (D) \\ 1 Institute of Physics and Electrotechnics, University of Sopron, H-9400 Sopron, Hungary; \\ joobne.preklet.edina@uni-sopron.hu (E.P.); tolvaj.laszlo@uni-sopron.hu (L.T.) \\ 2 Institute of Chemistry, University of Sopron, H-9400 Sopron, Hungary; visine.rajczi.eszter@uni-sopron.hu \\ * Correspondence: hofmann.tamas@uni-sopron.hu
}

Citation: Preklet, E.; Tolvaj, L.;

Visi-Rajczi, E.; Hofmann, T. Effect of Water Leaching on Photodegraded Scots Pine and Spruce Timbers Monitored by FTIR Spectroscopy. Forests 2021, 12, 833. https://doi.org/ $10.3390 /$ f12070833

Academic Editor: Brian K. Via

Received: 17 May 2021

Accepted: 22 June 2021

Published: 24 June 2021

Publisher's Note: MDPI stays neutral with regard to jurisdictional claims in published maps and institutional affiliations.

Copyright: (c) 2021 by the authors. Licensee MDPI, Basel, Switzerland. This article is an open access article distributed under the terms and conditions of the Creative Commons Attribution (CC BY) license (https:// creativecommons.org/licenses/by/ $4.0 /)$.
Abstract: The goal of this research was the systematic study and comparison of the divided individual effects of UV light irradiation and water leaching during artificial weathering. Spruce (Picea abies Karst.) and Scots pine (Pinus sylvestris L.) samples were irradiated by ultraviolet (UV) light. Another sequence of samples was treated with the combination of UV irradiation and water leaching. The total extent of UV treatment was 20 days for both series of samples. Time relation of UV irradiation and water leaching was 2:1. The chemical changes were observed by FTIR spectroscopy. The difference spectrum was used for determination of the chemical changes. Degradation of lignin was greater for the leached samples than for the pure UV treated samples. Scots pine suffered greater lignin degradation than spruce, and produced higher absorption increase on the absorption region of unconjugated carbonyls. The unconjugated carbonyl groups were the most responsive chemical elements to leaching. Spruce was more susceptible to leaching of unconjugated carbonyl groups than Scots pine. Two absorption bands of unconjugated carbonyl groups at 1706 and $1764 \mathrm{~cm}^{-1}$ wavenumbers were produced by photodegradation. The absorption band at $1764 \mathrm{~cm}^{-1}$ was more sensitive to water leaching than the band at $1706 \mathrm{~cm}^{-1}$.

Keywords: earlywood; ultraviolet irradiation; infrared spectroscopy; leaching by water; lignin; unconjugated carbonyls

\section{Introduction}

Sunlight, rain, heat, frost, air humidity, atmospheric pollutants and other environmental factors affect the surfaces of wooden objects placed outdoors [1,2]. The attractive colour hue and colour variety of wood is sensitive to these environmental factors. After some years, the wooden surface succumbs to greying. Greying is generated mainly by the leaching effect of rain. Rain is able to leach out the water-leachable extractives and partly leach out the degradation products of lignin [2,3]. Afterwards, the pure grey cellulose remains on the surface [4].

The most degradative phenomena for outdoor wooden constructions are sun radiation and the leaching effect of rain. The photodegradation of wood is a widely studied phenomenon [5-10]. The main chemical change generated by the photodegradation is the decomposition of lignin [11-15]. New carbonyl groups are generated as a product of lignin degradation [16-18].

Rate of photodegradation is partly determined by the applied temperature. In a previous research, we irradiated samples with UV emitter mercury lamp at 30, 80, 120, and $160{ }^{\circ} \mathrm{C}$ to investigate the effects of the temperature increases. The same light irradiation produced greater absorption change at $160{ }^{\circ} \mathrm{C}$ than at $30{ }^{\circ} \mathrm{C}$. "The simultaneous thermal and UV treatment was found to generate much greater absorption increase than the sum of absorption increases generated by the individual thermal treatment and UV radiation, separately" $[17,19]$. The investigations presented that the Arrhenius law was effective 
in interpreting the kinetics of photochemical alterations during the photodegradation of timber [20].

The leaching effect of rain is a recently studied phenomenon. Some research studied the effect of simultaneous light exposure and water leaching [21-23]. In these studies, the combined result of photodegradation and water leaching was investigated, but the individual effect of light irradiation and water leaching was not separated. A new paper studied the colour modification effect of water leaching during photodegradation of timber [3]. The leaching partly removed the chromophore molecules of the samples. The specimens become lighter by water leaching. The leaching effect of water on photodegraded hardwood species was studied in two new papers [24,25]. The time relation of UV radiation and water leaching was 2:1. The results are as follows: “Lignin degradation was found to be more intensive in leached samples than in purely UV-irradiated samples. Guaiacyl and syringyl lignin showed similar degradation properties. Unconjugated carbonyl groups generated by the photodegradation were the most sensitive chemical components to leaching. Photodegradation generated two absorption bands of unconjugated carbonyl groups at around the 1710 and $1760 \mathrm{~cm}^{-1}$ wavenumbers in the FTIR spectrum. The band at $1760 \mathrm{~cm}^{-1}$ was much more sensitive to water leaching than the band at $1710 \mathrm{~cm}^{-1}$. Three to ten days of water leaching was enough to remove all unconjugated carbonyls generated by the photodegradation, depending on the species. Sessile oak was the most sensitive species to water leaching, whereas black locust proved to be the most stable against both photodegradation and water leaching. Water was able to leach out unconjugated carbonyl groups (absorbing at $1745 \mathrm{~cm}^{-1}$ ) originally presented in all investigated hardwood species" [24]. One publication was found studying the leaching effect of water during photodegradation of spruce wood [26]. The results were similar as presented above for hardwood species. The time relation of UV radiation and water leaching was rather asymmetric $4: 1$, and the UV irradiation was continued only up to 10 days. The total leaching time was only 2.5 days. In accordance to the results described above, the current study chose a 2:1 time relation of UV radiation and water-leaching, and prolonged the treatment time of up to 20 days UV irradiation and 10 days water leaching.

The goal of this research was the systematic investigation and comparison of the individual effects of UV light irradiation and water leaching during accelerated weathering of spruce and Scots pine species. We intend to find the similarities and the differences between the weathering properties of Scots pine and spruce timbers.

\section{Materials and Methods}

For the investigations, the timber of spruce (Picea abies Karst.) and Scots pine (Pinus sylvestris L.) were chosen, as these are the most frequently processed softwoods by the Hungarian wood industry. Spruce timber is characterized by low extractive content while Scots pine contains moderate amount of extractives. One defect-free central board was used for sample preparation. The board contained 71- and 72-year rings for spruce and Scots pine, respectively, and the specimens were cut containing the thirty fifth year ring. The dimensions of samples were $30 \mathrm{~mm} \times 10 \mathrm{~mm} \times 5 \mathrm{~mm}$ (long. $\times$ tang. $\times$ rad.). Three samples were prepared for all investigated series. FTIR measurement was made on two fixed locations of the tangential surface of each sample. The measured surface of the samples contained only earlywood for determining the photodegradation properties of earlywood. Sun radiation and the leaching effect of the rain were imitated by the following experiments. After UV irradiation, the samples were submerged into distilled water at $22{ }^{\circ} \mathrm{C}$ (wet treatment). Leaching was carried out in a commercial pot. The UV irradiation was produced by a mercury vapour lamp with a total electric power of $800 \mathrm{~W}$. The power density of light radiation was $76 \mathrm{~W} / \mathrm{m}^{2}$ on the surface of the samples. The UV irradiation was $80 \%$ of the total emission of the lamp ( $31 \%$ UV-A, $24 \%$ UV-B, and $25 \%$ UV-C). The chamber temperature was $50{ }^{\circ} \mathrm{C}$. Samples were randomly rotated to ensure all samples receiving equivalent UV exposure. First cycle contained $24 \mathrm{~h} \mathrm{UV}$ irradiation, followed by $24 \mathrm{~h}$ water leaching. During the second cycle, the UV irradiation time was $48 \mathrm{~h}$ followed by 
$24 \mathrm{~h}$ water leaching. The second cycle was repeated for up to 20 days of UV irradiation and 10 days of water leaching (Table 1). The shorter UV radiation time was chosen at the beginning of the treatment because the degradation effect of UV radiation is very intensive at the beginning of the treatment. The second series of specimens was only exposed to UV irradiation without water leaching (dry treatment). Wet samples were dried at room temperature in total darkness to reach the initial weight. This procedure guarantied equal moisture content for infrared (IR) measurements. Measurements were carried out using an FTIR spectrophotometer (JASCO FT/IR 6300). The sample holder of the spectrophotometer guaranteed that always the same area of the sample was measured. The IR beam scanned approximately $12 \mathrm{~mm}^{2}$ area of the sample. Diffuse reflectance infrared Fourier transform (DRIFT) spectrum of the samples was measured before and after treatments. The average spectrum of 6 individual spectra were calculated for evaluation. Details of IR measurement and data manipulations are presented in a previous work [2].

Table 1. The order of UV irradiation and water leaching during the treatment.

\begin{tabular}{|c|c|c|c|}
\hline Cycles & UV Irradiation (UV) & Water Leaching $(\mathrm{w})$ & Result \\
\hline \multirow{2}{*}{ 1. cycle } & 1 day & & $1 \mathrm{UV}$ \\
\hline & & 1 day & $1 \mathrm{UV}+1 \mathrm{w}$ \\
\hline \multirow{2}{*}{ 2. cycle } & 2 days & & $3 \mathrm{UV}+1 \mathrm{w}$ \\
\hline & & 1 day & $3 \mathrm{UV}+2 \mathrm{w}$ \\
\hline \multirow{2}{*}{ 3. cycle } & 2 days & & $5 \mathrm{UV}+2 \mathrm{w}$ \\
\hline & & 1 day & $5 U V+3 w$ \\
\hline \multirow{2}{*}{ 4. cycle } & 2 days & & $7 \mathrm{UV}+3 \mathrm{w}$ \\
\hline & & 1 day & $7 \mathrm{UV}+4 \mathrm{w}$ \\
\hline \multirow{2}{*}{ 5. cycle } & 2 days & & $9 \mathrm{UV}+4 \mathrm{w}$ \\
\hline & & 1 day & $9 \mathrm{UV}+5 \mathrm{w}$ \\
\hline \multirow{2}{*}{ 6. cycle } & 2 days & & $11 \mathrm{UV}+5 \mathrm{w}$ \\
\hline & & 1 day & $11 \mathrm{UV}+6 \mathrm{w}$ \\
\hline \multirow{2}{*}{ 7. cycle } & 2 days & & $13 \mathrm{UV}+6 \mathrm{w}$ \\
\hline & & 1 day & $13 \mathrm{UV}+7 \mathrm{w}$ \\
\hline \multirow{2}{*}{ 8. cycle } & 2 days & & $15 \mathrm{UV}+7 \mathrm{w}$ \\
\hline & & 1 day & $15 \mathrm{UV}+8 w$ \\
\hline \multirow{2}{*}{ 9. cycle } & 2 days & & $17 \mathrm{UV}+8 \mathrm{w}$ \\
\hline & & 1 day & $17 \mathrm{UV}+9 \mathrm{w}$ \\
\hline \multirow{2}{*}{ 10. cycle } & 3 days & & $20 U V+9 w$ \\
\hline & & 1 day & $20 U V+10 w$ \\
\hline
\end{tabular}

\section{Results and Discussion}

The chemical changes produced by the UV irradiation and water leaching were monitored by diffuse reflectance IR spectroscopy. This method is useful for studying the chemical effects within a thin surface layer. Fortunately, photodegradation produces changes within the same layer. Figure 1 represents the difference spectrum of Scots pine and spruce species created by one day and by nine days of UV irradiation, respectively. The fingerprint region (900-1900 $\mathrm{cm}^{-1}$ ) is presented in this study. This region shows most of chemical changes caused by photodegradation. One-day UV irradiation was enough to generate clearly visible changes. The absorption of guaiacyl lignin around $1510 \mathrm{~cm}^{-1}$ decreased $[2,17,27]$. This negative change was visible together with the absorption reduction of the aromatic C-H deformation at $1469 \mathrm{~cm}^{-1}$ and with the absorption reduction of the guaiacyl ring breathing at $1269 \mathrm{~cm}^{-1}$. The free radicals produced by the photodegradation react with oxygen and produce unconjugated carbonyl groups. Many studies have analysed the overview of the large number of carbonyl compounds formed during the photodegradation of lignin [28-32]. 


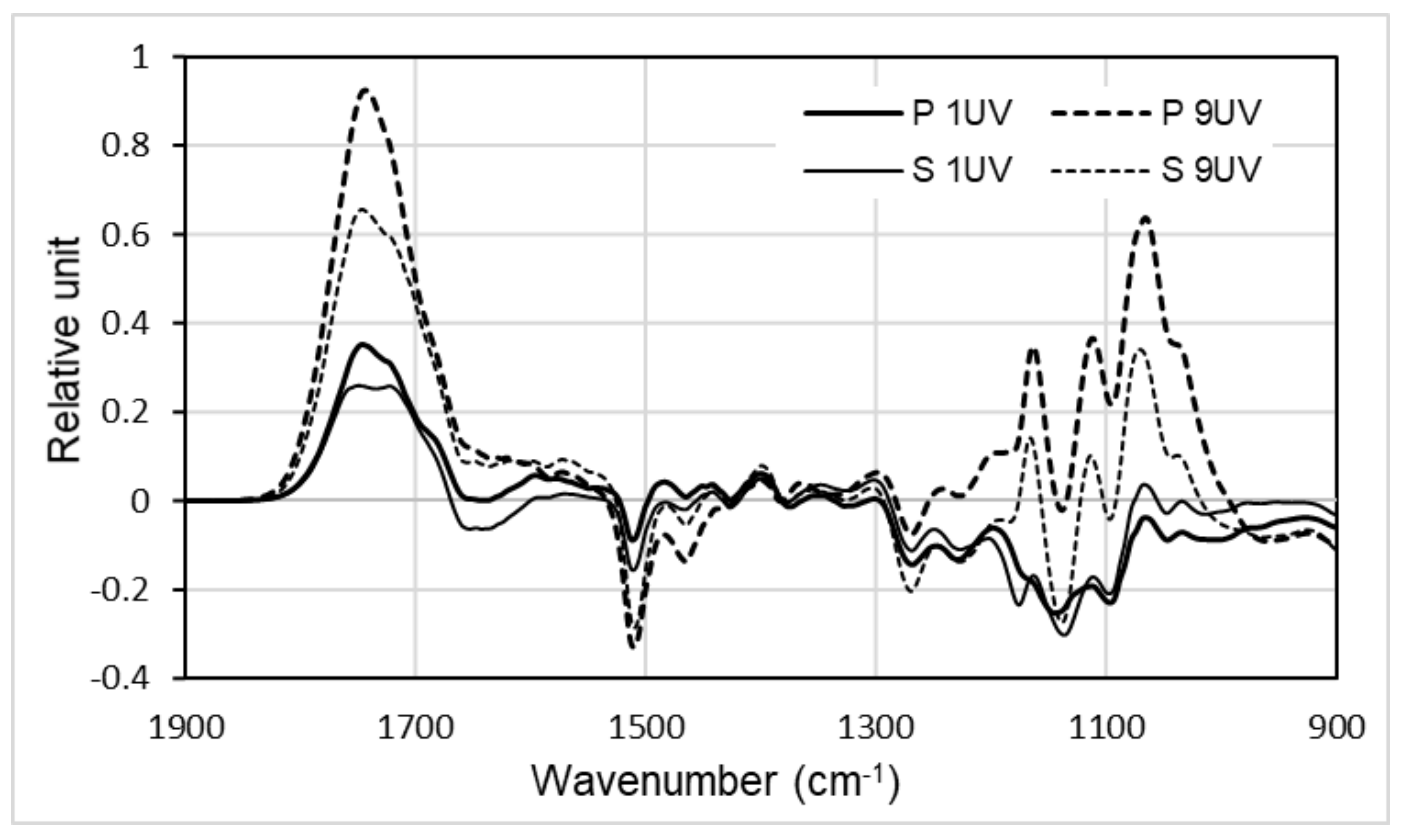

Figure 1. Difference FTIR spectra of Scots pine (P) and spruce (S) species generated by one-day and nine-day UV irradiation.

The newly generated unconjugated carbonyl groups absorb between 1650 and $1820 \mathrm{~cm}^{-1}$. This broad band is a sum of individual absorption bands. The spectrum of spruce consists of 3 absorption bands generated by one-day UV irradiation. Two maxima around 1706 and $1764 \mathrm{~cm}^{-1}$ and a shoulder around the $1690 \mathrm{~cm}^{-1}$ wavenumbers are clearly visible. The band at $1764 \mathrm{~cm}^{-1}$ belongs to the absorption of $\mathrm{CO}$ stretching for unconjugated ketones and $\gamma$ lactones produced by the oxidation after the degradation of the aromatic ring. The aliphatic carboxyl groups absorb at $1705 \mathrm{~cm}^{-1}$. The absorption increase of Scots pine shows only one real maximum and two shoulders after one-day of UV irradiation. The prolonged irradiation time amplified the absorption changes of both the aromatic ring and the unconjugated carbonyl groups. The effect of nine-day irradiation is presented in Figure 1 as well. The nine-day treatment produced one integrated absorption increase with a maximum at $1748 \mathrm{~cm}^{-1}$. The shoulders are hardly visible. The visible band is the mathematical integration of the overlapping individual bands. The figure below clearly illustrates that the visible band is sometimes not a real one but occurs if the individual bands highly overlap each other.

Two absorption decreases can be seen at 1174 and $1137 \mathrm{~cm}^{-1}$. The first decrease represents the asymmetric stretching of the ether bond while the second decrease shows the symmetric stretching of the ether bond together whit the aromatic $\mathrm{C}-\mathrm{H}$ deformation and the glucose ring vibration. These absorption decreases present the ether bond splitting and the degradation of cellulose [5]. There is an absorption decrease at $1096 \mathrm{~cm}^{-1}$, but the meaning of this absorption decrease is unknown. The nine-day irradiation generated unusual changes in the $1000-1200 \mathrm{~cm}^{-1}$ wavenumber region. Absorption increases are visible for both examined conifers in this whole wavenumber region. This is not a real absorption increase in a wide wavenumber interval. The Kubelka-Munk equation does not generate the absorption spectrum correctly for intensive absorption bands if the surface roughness alters. This phenomenon lifts up the difference spectrum. The spruce spectrum shows a moderate lifting effect, but the pine spectrum shows a major lifting effect. Nine-day UV irradiation produced much greater absorption decrease at the $1137 \mathrm{~cm}^{-1}$ wavenumber than one-day treatment did. Though it is clearly visible for spruce, this negative band seems to be a positive valley between two positive bands for pine. The lifting effect created this anomaly. The large K-M value increase covers the real absorption changes, preventing the assessment of IR spectrum in the $1000-1200 \mathrm{~cm}^{-1}$ wavenumber region. The current 
study will disregard discussion of the changes in the $1000-1200 \mathrm{~cm}^{-1}$ interval. A previous work gives detailed discussion of this phenomenon [33].

As mentioned above, the broad absorption band of unconjugated carbonyls is the integration of two absorption bands. Knowing the exact place of the maxima of the bands is important. Figure 1 demonstrates that lower intensity generates greater separation between the bands. The photodegradation properties of spruce latewood can help to find the exact place of the individual maximum of the bands. Figure 2 presents the difference spectra of both earlywood and latewood for Scots pine and spruce species produced by one-day UV irradiation. (The spectra of latewood samples were borrowed from a parallel investigation, where the photodegradation behaviours of earlywood and latewood were studied [34].) The latewood part of spruce is less sensitive to photodegradation than earlywood, and the two bands are well separated. That is why this latewood is suitable for finding the proper place of the two maxima. These two maxima are located at the 1706 and $1764 \mathrm{~cm}^{-1}$ wavenumbers. This figure assuredly demonstrates that the increasing rate of overlapping pushes the places of maxima towards each other. The intensity differences between the two bands also determine the place of the visible maximum. The shapes of the absorption bands of unconjugated carbonyls for Scots pine and spruce are mainly identical. This finding gives us the possibility to use the same two wavenumbers as the place of maxima for both investigated conifer species as the place of maxima.

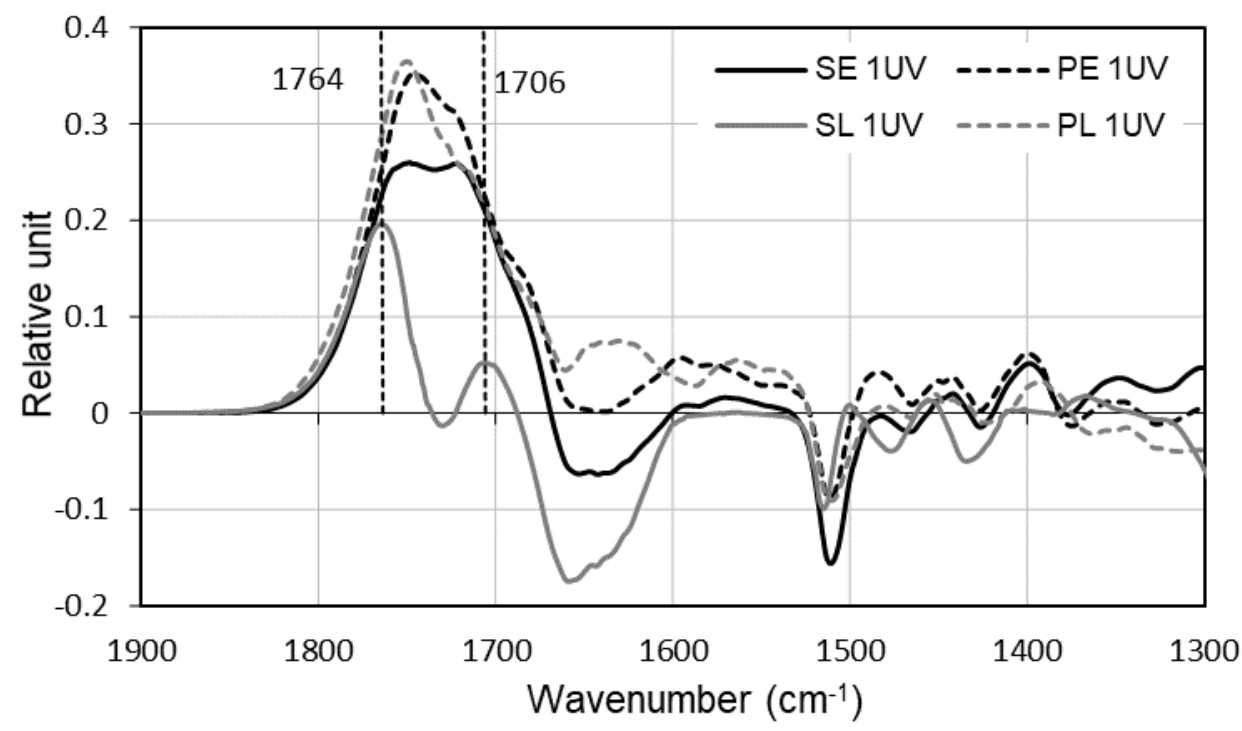

Figure 2. Difference FTIR spectra of earlywood (E) and latewood (L) for Scots pine (P) and spruce (S) species generated by one-day UV irradiation.

Figures 3 and 4 present the effects of UV treatment and water leaching for Scots pine and spruce samples, respectively. The thin solid line presents the chemical changes after one-day UV treatment (1 UV). The thick solid line shows the effect of one-day water leaching $(1 \mathrm{UV}+1 \mathrm{w})$, and the dotted line represents the effect of two-day UV irradiation after the first water leaching $(3 \mathrm{UV}+1 \mathrm{w})$. (The intensity interval of the vertical axes is the same for Figures 3-6 to keep the correct comparison.)

The leaching did not modify the intensity decrease of the lignin band at the $1510 \mathrm{~cm}^{-1}$ wavenumber, but the next two-day UV irradiation generated further lignin degradation for both Scots pine and spruce specimens. Detailed alteration of this lignin band will be discussed later. The UV radiation produced larger absorption increase in the unconjugated carbonyl region (between 1650 and $1820 \mathrm{~cm}^{-1}$ ) for Scots pine than for spruce. The presence of two absorption bands is decidedly visible for both Scots pine and spruce species. The first water leaching reduced the absorption intensity of the unconjugated carbonyl groups at 1706 and $1764 \mathrm{~cm}^{-1}$ in different way. The band at $1764 \mathrm{~cm}^{-1}$ showed greater leaching effect than the band at $1706 \mathrm{~cm}^{-1}$. The band at $1764 \mathrm{~cm}^{-1}$ became hardly visible for 
spruce. Spruce samples presented greater absorption decrease than Scots pine samples in the whole unconjugated carbonyl region caused by water leaching. The two-day UV irradiation (after water leaching) created further lignin degradation and unconjugated carbonyl group production, presented by negative absorption increase at $1510 \mathrm{~cm}^{-1}$ and positive absorption increase between 1650 and $1820 \mathrm{~cm}^{-1}$. Scots pine showed greater changes than spruce from both the viewpoint of lignin degradation and the viewpoint of unconjugated carbonyls generation.

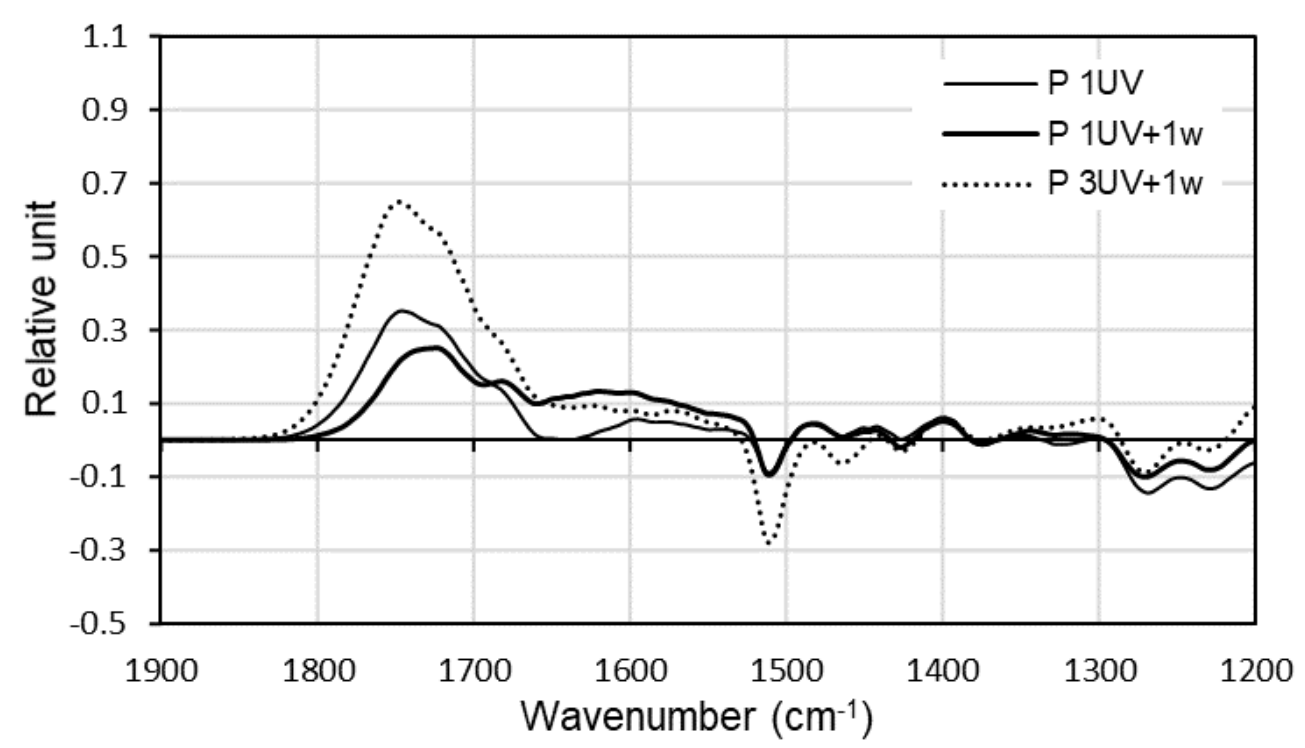

Figure 3. Difference FTIR spectra of Scots pine (P). $1 \mathrm{UV}=$ one-day UV irradiation; $x U V+y w$ is an abbreviation where $\mathrm{x}$ is the extent of UV irradiation, and $\mathrm{y}$ is the extent of water leaching in days.

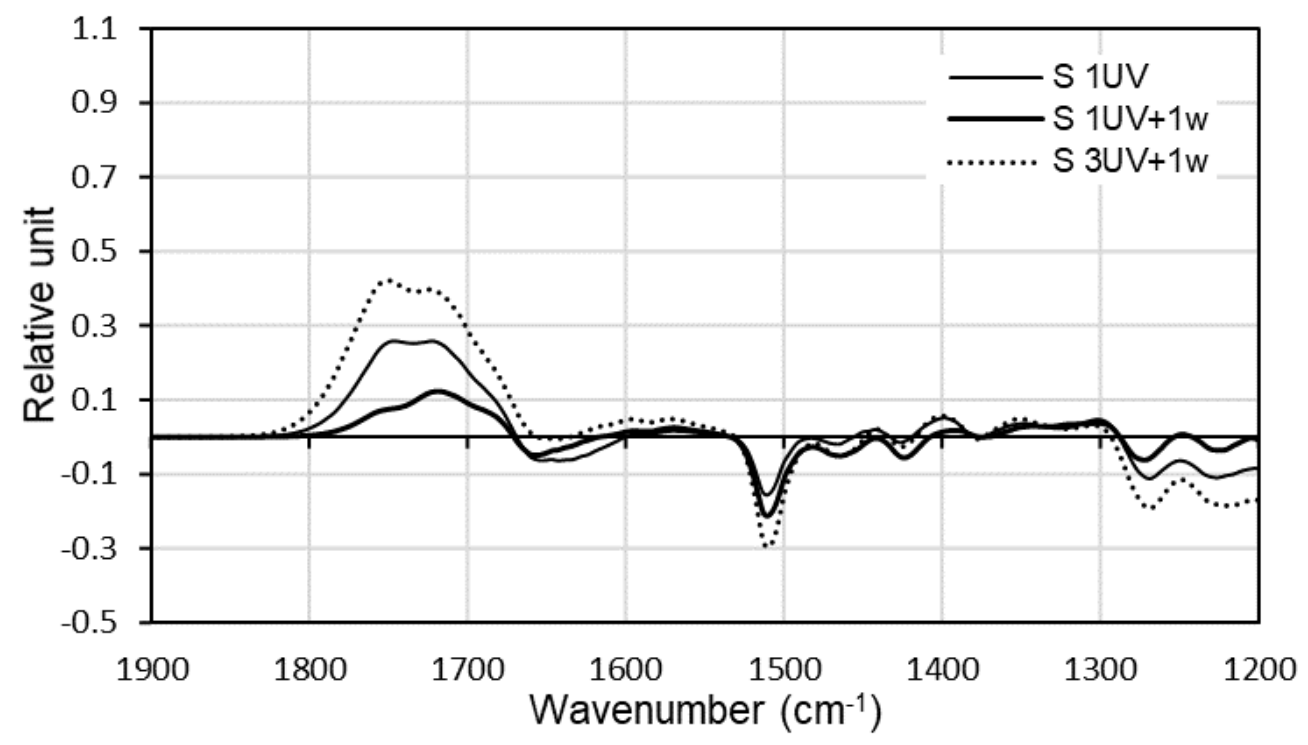

Figure 4. Difference FTIR spectra of spruce (S). $1 \mathrm{UV}=$ one-day UV irradiation; $x U V+y w$ is an abbreviation where $\mathrm{x}$ is the extent of UV irradiation, and $\mathrm{y}$ is the extent of water leaching in days. 


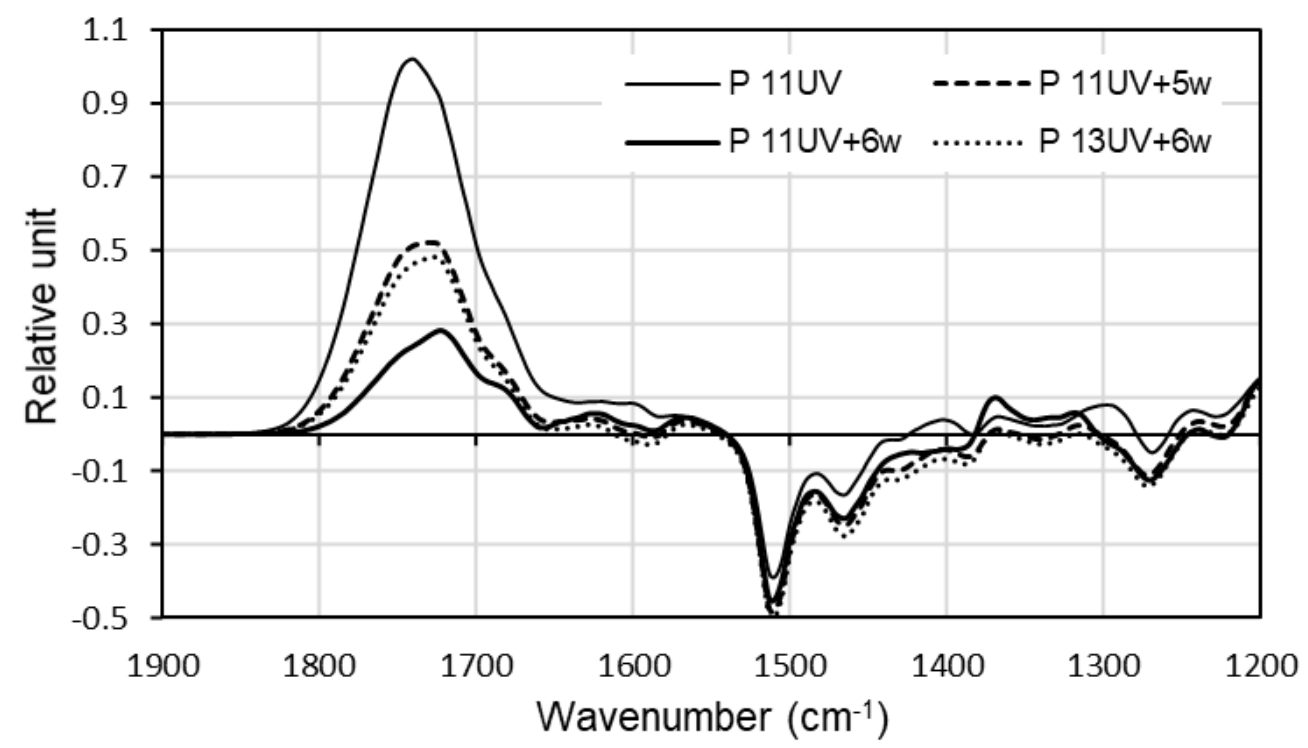

Figure 5. Difference FTIR spectra of Scots pine $(p)$. $11 \mathrm{UV}=$ eleven-day UV irradiation; $x U V+y w$ is an abbreviation where $\mathrm{x}$ is the extent of $\mathrm{UV}$ irradiation, and $\mathrm{y}$ is the extent of water leaching in days.

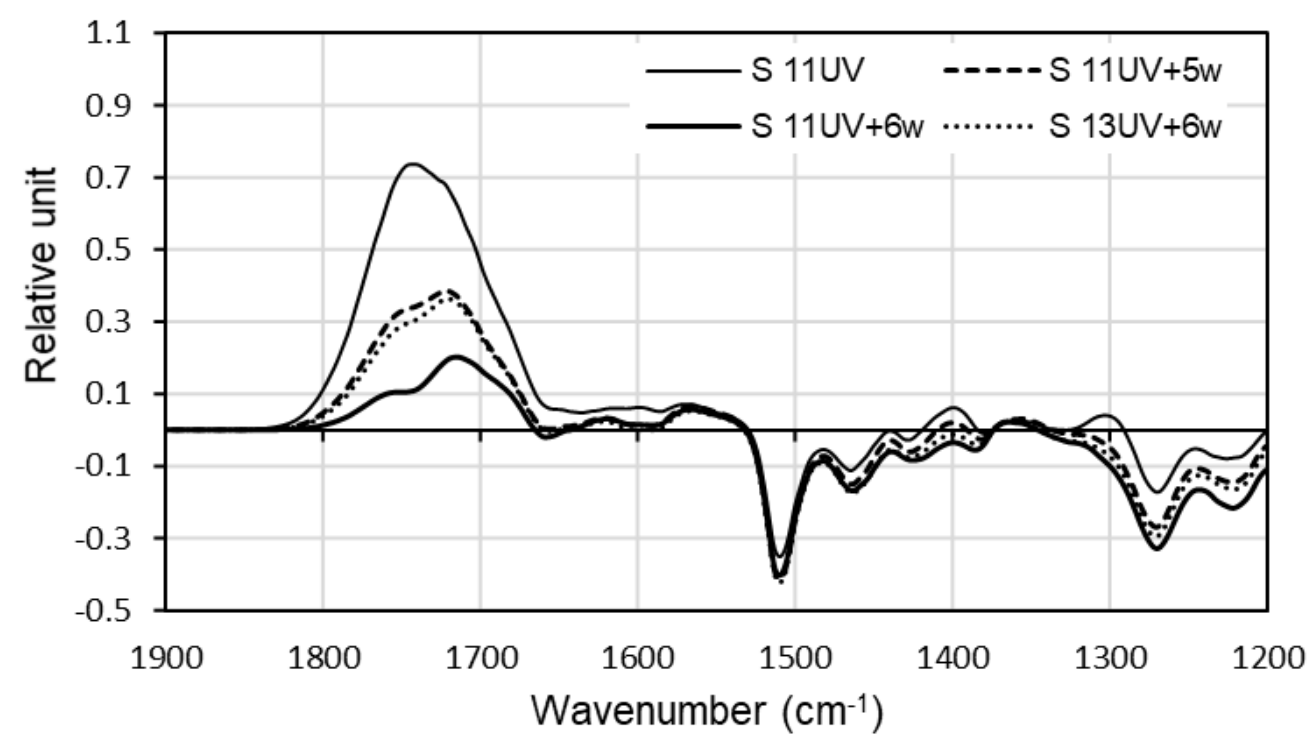

Figure 6. Difference FTIR spectra of spruce (S). $11 \mathrm{UV}=$ eleven-day UV irradiation; $x U V+y w$ is an abbreviation where $\mathrm{x}$ is the extent of UV irradiation, and $\mathrm{y}$ is the extent of water leaching in days.

The negative intensity of absorption change for the aromatic ring at $1510 \mathrm{~cm}^{-1}$ increased continuously during further treatment cycles. This increase was slow for spruce, but the increase was a little faster in the first 11 days of UV irradiation for Scots pine than for spruce. Figures 5 and 6 present the absorption changes after 11-day UV treatment for Scots pine and spruce, respectively. These figures do not clearly show the intensity differences for the negative lignin band at $1510 \mathrm{~cm}^{-1}$ because the individual curves highly overlap each other. However, the figures visibly show that Scots pine suffered greater lignin degradation than spruce.

The number of newly generated unconjugated carbonyl groups was greater for Scots pine than for spruce. The maximum intensity value of the unconjugated carbonyl band was 1.01 and 0.72 after 11-day pure UV irradiation (11 UV) for Scots pine and spruce, respectively. These intensity values were reduced considerably by leaching $(11 \mathrm{UV}+6 \mathrm{w})$. The bands at $1764 \mathrm{~cm}^{-1}$ mostly disappeared and remained visible as shoulder after 6-day leaching. The 6-day leaching reduced the band intensity at $1706 \mathrm{~cm}^{-1}$ as well. The intensity 
values were reduced up to 0.27 and 0.19 by 6-day leaching for Scots pine and spruce, respectively. The next 2-day UV irradiation $(13 \mathrm{UV}+6 \mathrm{w})$ generated new unconjugated carbonyl groups producing absorption increase. This absorption increase was able to compensate the effect of the previous water leaching, generating the same curve as (11 UV $+5 \mathrm{w}$ ) produced. This tendency remained up to the end of treatments; only the peak intensities decreased slightly.

Figures 3-6 show the difference IR spectra generated during the 20-day treatments. Figure 7 represents the absorption changes of spruce at the $1510 \mathrm{~cm}^{-1}$ wavenumber. This absorption represents the vibration of the aromatic ring in guaiacyl lignin. Negative values imply the breaking of the aromatic ring generated by UV irradiation. The first empty column in Figure 7 represents the effect of one-day UV irradiation, followed by the columns of repeated one-day water leachings and two-day UV irradiations. The photodegradation of guaiacyl lignin was intensive during the first day of UV irradiation. The next two-day irradiations produced moderate absorption intensity decreases up to the thirteenth day for spruce. There is an abnormal intensity decrease at 7-day UV irradiation. This anomaly is visible in all similar figures (Figures 7-10). The reason might be that the mercury lamp was not operational for a few hours due to a power outage. (This anomaly was ignored during further evaluation.) The intensity of the lignin band at $1510 \mathrm{~cm}^{-1}$ did not change during the leaching processes. Leached specimens presented considerably larger lignin degradation compared to the samples receiving pure UV irradiation. The reason for this phenomenon can be that water leaching generated further opportunity for the UV radiation to degrade the lignin in deeper layers of the specimens. Scots pine samples presented similar changes at the $1510 \mathrm{~cm}^{-1}$ wavenumber compared to spruce, only the intensities were greater. The maximum absorption intensity changes were -0.36 for pure UV irradiated samples and -0.45 for UV irradiated + leached samples for spruce. The same type of intensities for Scots pine were -0.42 and -0.52 . For pure UV irradiated samples, 15 days were enough to generate the maximum lignin degradation. In contrast, leached samples produced continuously increasing lignin degradation during the 20-day UV irradiation. The chosen UV irradiation and leaching times were not long enough to determine the maximum of lignin degradation.

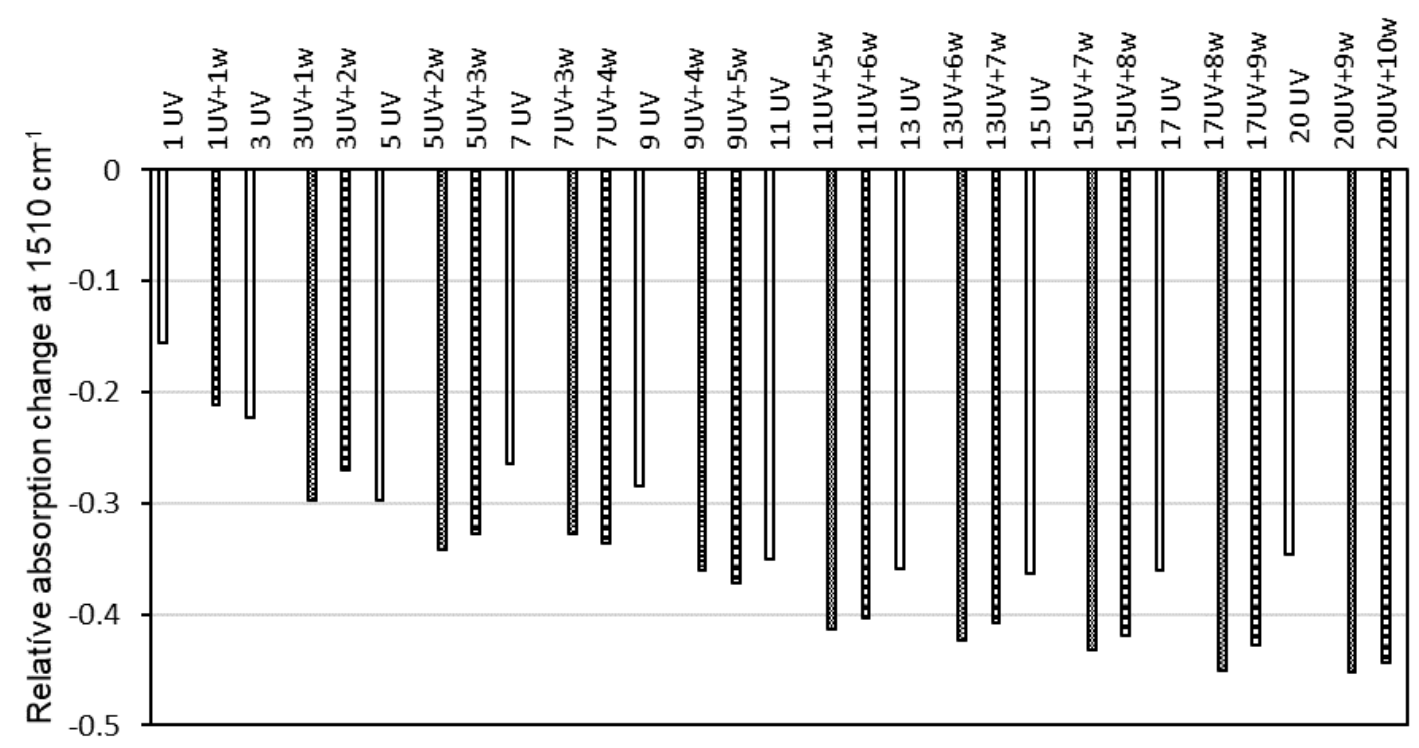

Figure 7. Absorption change of guaiacyl lignin in spruce at $1510 \mathrm{~cm}^{-1}$. Empty columns show the effect of pure UV irradiation. $x U V=x$-day $U V$ irradiation; $x U V+y w$ is an abbreviation where $x$ is the extent of $U V$ irradiation, and $y$ is the extent of water leaching in days. 


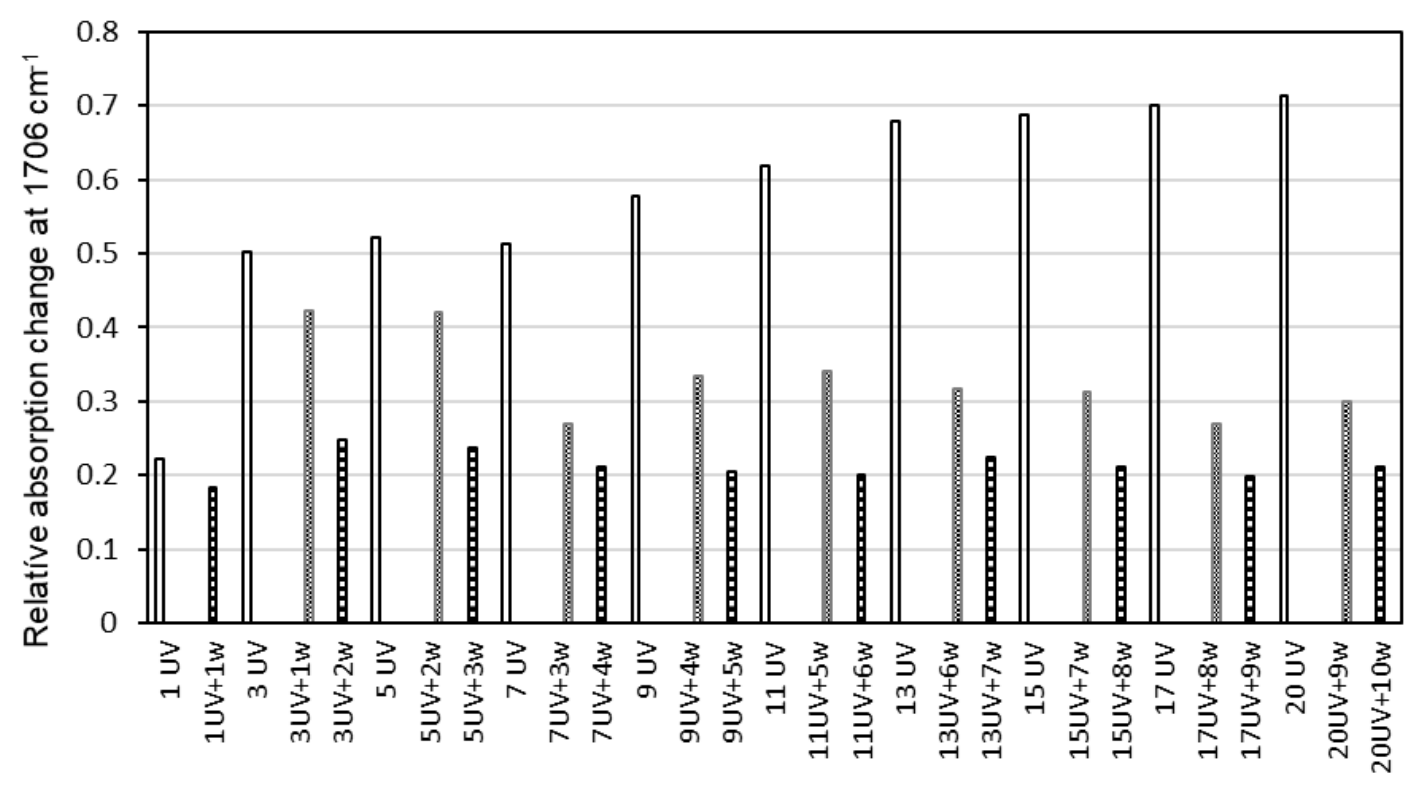

Figure 8. Absorption change of the unconjugated carbonyls at $1706 \mathrm{~cm}^{-1}$ for Scots pine. Empty columns show the effect of pure UV irradiation. $x U V=x$-day $U V$ irradiation; $x U V+y w$ is an abbreviation where $x$ is the extent of UV irradiation, and $\mathrm{y}$ is the extent of water leaching in days.

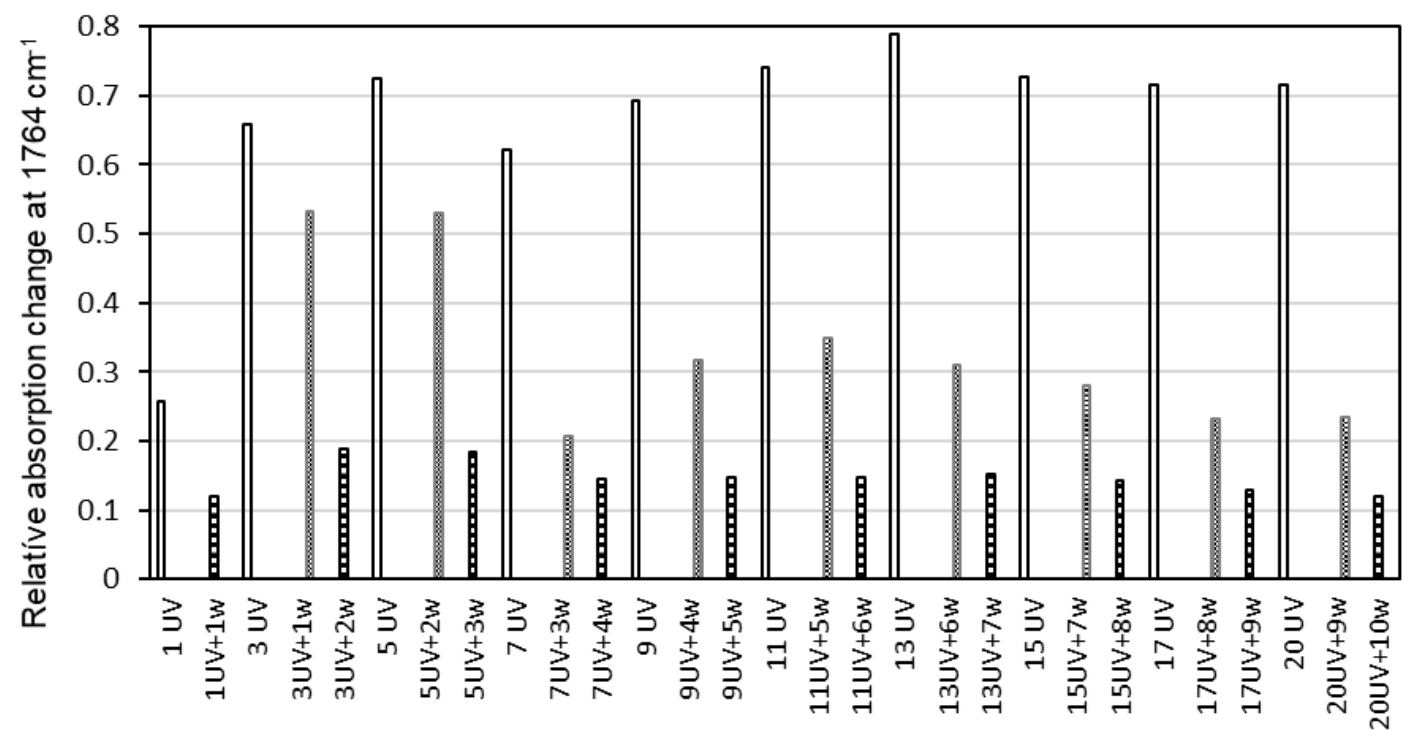

Figure 9. Absorption change of the unconjugated carbonyls at $1764 \mathrm{~cm}^{-1}$ for Scots pine. Empty columns show the effect of pure $\mathrm{UV}$ irradiation. $\mathrm{xUV}=\mathrm{x}$-day $\mathrm{UV}$ irradiation; $\mathrm{xUV}+\mathrm{yw}$ is an abbreviation where $\mathrm{x}$ is the extent of $\mathrm{UV}$ irradiation, and $\mathrm{y}$ is the extent of water leaching in days.

Lignin degradation increased the number of unconjugated carbonyl groups. Time dependence of this phenomenon is presented in Figures 8-10. The time dependence of unconjugated carbonyls absorbing at $1706 \mathrm{~cm}^{-1}$ is presented in Figure 8 for Scots pine. The absorption increase was rapid up to the third day of UV treatment. This was followed by a continuous but moderate absorption increase for pure UV treated samples. The leached samples followed the changing tendency of pure UV treated samples up to the third day of leaching. After this period, the two types of changes diverged from each other. The new two-day UV irradiations always produced new unconjugated carbonyl groups, but the next water leaching reduced the number of carbonyl groups up to a constant level during the total examined period. This constant level was 0.2 unit for both investigated species. The first leaching alienated $18 \%$ of the carbonyls absorbing at $1706 \mathrm{~cm}^{-1}$ and the 
last (tenth) leaching also reduced by $29 \%$. The maximum reduction was $44 \%$ during the third leaching period. Spruce samples showed properties that were similar to those of Scots pine. Not only the tendencies were similar, but the absorption values were similar as well. The leaching data of spruce were: first leaching, $49 \%$ (it was the maximum as well), and last leaching, $38 \%$. These data show that spruce species were more sensitive to leaching than Scots pine.

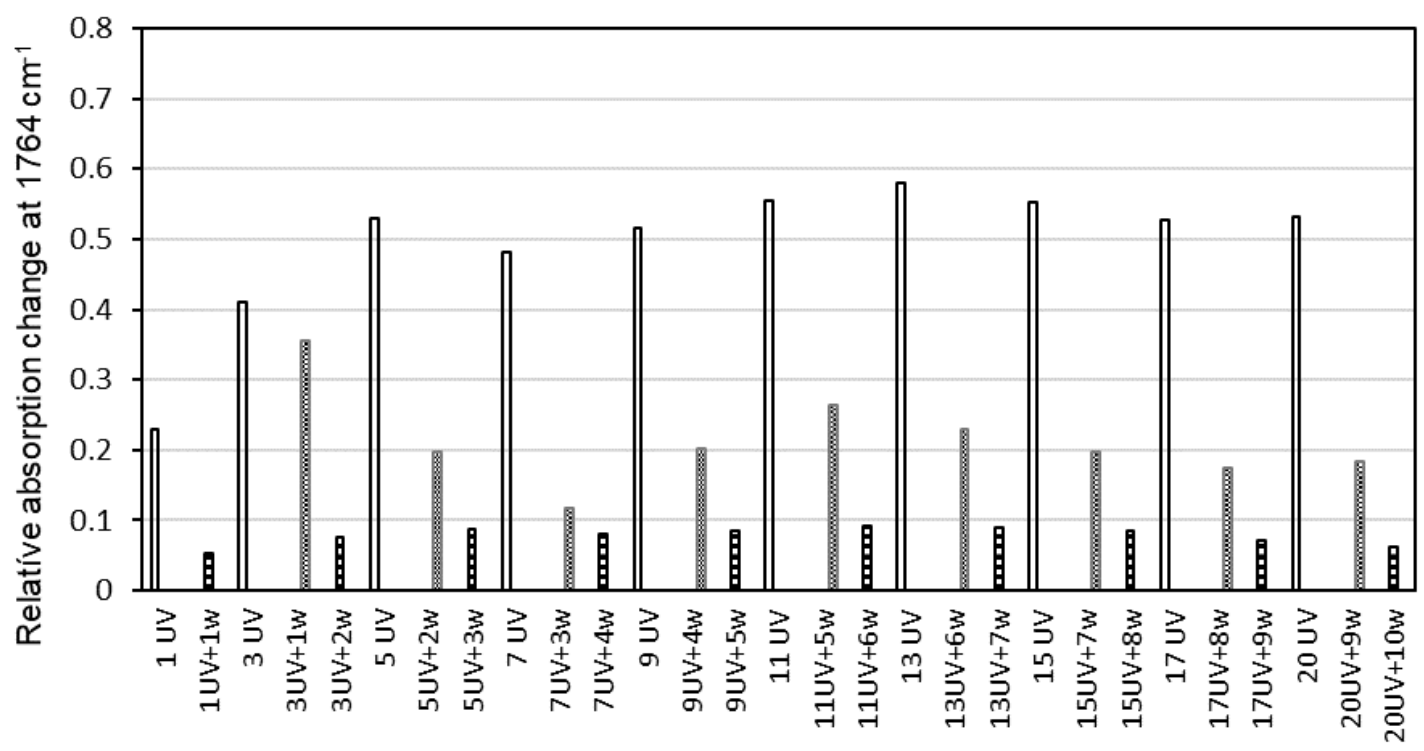

Figure 10. Absorption change of the unconjugated carbonyls at $1764 \mathrm{~cm}^{-1}$ for spruce. Empty columns show the effect of pure UV irradiation. $x U V=x$-day $U V$ irradiation; $x U V+y w$ is an abbreviation where $x$ is the extent of UV irradiation, and $\mathrm{y}$ is the extent of water leaching in days.

Figures 9 and 10 represent the absorption changes of unconjugated carbonyl groups absorbing at $1764 \mathrm{~cm}^{-1}$ wavenumber for Scots pine and spruce, respectively. Changing tendencies of absorption intensities were similar for both investigated species. Differences were found in the intensity values. Samples receiving only UV irradiation presented a rapid absorption increase during the first five days of treatment. This intensity increase was slow up to the thirteenth day of irradiation and continued to slow down until the end of treatment. The maximum absorption intensity changes were 0.79 for pure UV irradiated samples and 0.53 for UV irradiated + leached samples for Scots pine. Spruce samples produced smaller absorption increase at $1764 \mathrm{~cm}^{-1}$ than Scots pine did. The same type of intensities for spruce were 0.58 and 0.36 . The leached samples followed the changing tendency of pure UV treated samples up to the third day of treatment. After this period, the two types of changes diverged. The new two-day UV irradiations always produced new unconjugated carbonyl groups, but the next water leaching reduced the number of carbonyl groups considerably. This reduction produced almost constant absorption values (slightly below 0.1 unit) for spruce. The similar intensity values were between 0.2 and 0.1 for Scots pine showing slow intensity decrease. The first leaching reduced $54 \%$ of the carbonyls absorbing at $1764 \mathrm{~cm}^{-1}$, and the last leaching reduced $48 \%$. The maximum reduction was $65 \%$ during the second leaching period. Spruce samples showed similar leaching properties as Scots pine, but the leaching was much more effective. The leaching data of spruce were the following: first leaching, $77 \%$, last leaching, $66 \%$, and the maximum was $79 \%$ during the second leaching period. These data show that spruce species were much more sensitive to leaching than Scots pine.

The results present the diverse leaching properties of the two investigated unconjugated carbonyl groups. Time dependence of the absorption change at $1764 \mathrm{~cm}^{-1}$ was similar to the time dependence of the guaiacyl lignin degradation. In contrast, the time dependence of the absorption increase at $1706 \mathrm{~cm}^{-1}$ did not follow the changing tendency 
of the lignin band at $1510 \mathrm{~cm}^{-1}$. Consequently, the absorption increase at $1706 \mathrm{~cm}^{-1}$ must be related to the degradation of cellulose and/or hemicelluloses. The origin of the absorption increase at $1706 \mathrm{~cm}^{-1}$ needs further chemical investigation.

\section{Conclusions}

A series of spruce and Scots pine specimens was irradiated by UV light. The second series of samples was treated with the combination of UV radiation and water leaching. The FTIR measurement was completed after both UV radiation and water leaching to determine both effects separately.

1. Leached samples produced greater lignin degradation than in purely UV treated samples. This finding presents that the leaching effect of rain opens deeper layers for UV degradation raising the rate of degradation of the timber.

2. Scots pine suffered greater lignin degradation than spruce and produced higher absorption increase on the absorption region of unconjugated carbonyls. Unconjugated carbonyl groups showed the greatest sensitive to leaching. Spruce was more susceptible to leaching of unconjugated carbonyl groups than Scots pine. These results show that both Scots pine and spruce timbers need proper surface finishing in case of outdoor applications.

3. For pure UV irradiated samples, 15 days were enough to generate the maximum lignin degradation. In contrast, leached samples produced continuously increasing lignin degradation during the 20-day UV irradiation. The chosen UV irradiation and leaching times were not long enough to determine the maximum of lignin degradation. These results highlight that combined UV irradiation and water leaching generate degradation of wood in deeper layers than the treatments separately.

4. The photodegradation produced two absorption increases in the unconjugated carbonyl region at 1706 and $1764 \mathrm{~cm}^{-1}$ wavenumbers. The absorption band at 1764 $\mathrm{cm}^{-1}$ showed much greater leaching effect than the band at $1706 \mathrm{~cm}^{-1}$. These results strengthen the different origin of these two types of absorption increases.

Author Contributions: Conceptualization, E.P., L.T., and T.H.; methodology, E.P., L.T., E.V.-R. and T.H.; software, L.T. and T.H.; validation, E.P., L.T. and T.H.; formal analysis, E.P., L.T., E.V.-R. and T.H.; investigation, E.P., L.T., E.V.-R. and T.H.; resources, E.P., L.T. and E.V.-R.; data curation, E.P., L.T., E.V.-R. and T.H.; writing —original draft preparation, L.T. and E.V.-R.; writing-review and editing, T.H.; visualization, E.P., L.T. and E.V.-R.; supervision, L.T. All authors have read and agreed to the published version of the manuscript.

Funding: The research was made in frame of the "EFOP-3.6.1-16-2016-00018 - Improving the role of research, development, and innovation in higher education through institutional developments assisting intelligent specialization in Sopron and Szombathely".

Institutional Review Board Statement: Not applicable.

Informed Consent Statement: Not applicable.

Data Availability Statement: The data presented in this study are available on request from the corresponding author. The data are not publicly available due to their complexity.

Conflicts of Interest: The authors declare no conflict of interest.

\section{References}

1. Evans, P.D. Weathering and photoprotection of wood. In Development of Commercial Wood Preservatives. Efficacy, Environmental, and Health Issues; Schultz, T.P., Militz, H., Freeman, M.H., Goodbel, B., Nicholas, D.D., Eds.; American Chemical Society: Washington, DC, USA, 2008; pp. 69-117.

2. Csanady, E.; Magoss, E.; Tolvaj, L. Quality of Machined Wood Surfaces; Springer: Berlin/Heidelberg, Germany, $2015 ;$ pp. 41-91.

3. Kannar, A.; Tolvaj, L.; Magoss, E. Colour change of photodegraded spruce wood by water leaching. Wood Res. 2018, 63, 935-946.

4. Tolvaj, L.; Papp, G. Outdoor Weathering of Impregnated and Steamed Black Locust. In Proceedings of the ICWSF'99 Conference, Missenden Abbey, UK, 14-16 July 1999; pp. 112-115. 
5. Tolvaj, L.; Faix, O. Artificial Ageing of Wood Monitored by DRIFT Spectroscopy and CIE L*a*b* Color Measurements. I. Effect of UV Light. Holzforschung 1995, 49, 397-404. [CrossRef]

6. Pandey, K.K. Study of the effect of photo-irradiation on the surface chemistry of wood. Polym. Degrad. Stab. 2005, 90, 9-20. [CrossRef]

7. Agresti, G.; Bonifazi, G.; Calienno, L.; Capobianco, G.; Lo Monaco, A.; Pelosi, C.; Picchio, R.; Serranti, S. Surface investigation of photo-degraded wood by colour monitoring, infrared spectroscopy, and hyperspectral imaging. J. Spectrosc. 2013, 1, 380536. [CrossRef]

8. Broda, M.; Popescu, C.M. Natural decay of archaeological oak wood versus artificial degradation processes-An FT-IR spectroscopy and X-ray diffraction study. Spectrochim. Acta A Mol. Biomol. Spectrosc. 2019, 209, 280-287. [CrossRef] [PubMed]

9. Liu, X.Y.; Timar, M.C.; Varodi, A.M.; Yi, S.L. Effects of Ageing ont he Color and Surface Chemistry of Paulownia Wood (P. elongata) from Fast Growing Crops. BioRes 2016, 11, 9400-9420. [CrossRef]

10. Liu, X.Y.; Liu, M.; Lv, M.Q.; Lv, J.F. Photodegradation of Three Hardwood Species by Sunlight and Xenon Light Source. BioRes 2019, 14, 6909-6922.

11. Pandey, K.K.; Vuorinen, T. Comparative study of photodegradation of wood by a UV laser and a xenon light source. Polym. Degrad. Stab. 2008, 93, 2138-2146. [CrossRef]

12. Popescu, C.M.; Popescu, M.C.; Vasile, C. Structural analysis of photodegraded lime wood by means of FT-IR and 2D IR correlation spectroscopy. Int. J. Biol. Macromol. 2011, 48, 667-675. [CrossRef]

13. Cogulet, A.; Blanchet, P.; Landry, V. Wood degradation under UV irradiation: A lignin characterization. J. Photochem. Photobiol. B Biol. 2016, 158, 184-191. [CrossRef]

14. Timar, M.C.; Varodi, A.M.; Gurau, L. Comparative study of photodegradation of six wood species after short-time UV exposure. Wood Sci. Technol. 2016, 50, 135-163. [CrossRef]

15. Arpaci, S.S.; Tomek, E.D.; Ermeydan, M.A.; Yildirim, I. Natural weathering of sixteen wood species: Changes on surface properties. Polym. Degrad. Stab. 2020, 183, 109415. [CrossRef]

16. Bonifazi, G.; Calienno, L.; Capobianco, G.; Lo Monaco, A.; Pelosi, C.; Picchio, R.; Serranti, S. A new approach for the modelling of chestnut wood photo-degradation monitored by different spectroscopic techniques. Environm. Sci. Poll Res. 2017, 24, 13874-13884 [CrossRef]

17. Varga, D.; Tolvaj, L.; Tsuchikawa, S.; Bejo, L.; Preklet, E. Temperature dependence of wood photodegradation monitored by infrared spectroscopy. J. Photochem. Photobiol. A Chem. 2017, 348, 219-225. [CrossRef]

18. Jankowska, A.; Rybak, K.; Nowacka, M.; Boruszewski, P. Insight of Weathering Processes Based on Monitoring Surface Characteristic of Tropical Wood Species. Coat 2020, 10, 877. [CrossRef]

19. Tolvaj, L.; Molnar, Z.; Nemeth, R. Photodegradation of wood at elevated temperature: Infrared spectroscopic study. J. Photochem. Photobiol. B Bilol. 2013, 121, 32-36. [CrossRef]

20. Preklet, E.; Tolvaj, L.; Bejo, L.; Varga, D. Temperature dependence of wood photodegradation. Part 2: Evaluation by Arrhenius law. J. Photochem. Photobiol. A Chem. 2018, 356, 329-333.

21. Kamdem, P.; Greiler, S. Surface roughness and color change of cooper amine and UV absorber-treated red maple (Acer rubrum) exposed to artificial ultraviolet light. Holzforschung 2002, 56, 473-478. [CrossRef]

22. Hansmann, C.; Deka, M.; Wimmer, R.; Gindl, W. Artificial weathering of wood surfaces modified by melamine formaldehyde resin. Holz. Roh. Werkst. 2006, 64, 198-203. [CrossRef]

23. Fufa, S.M.; Jelle, B.P.; Hovde, P.J. Weathering performance of spruce coated with water based acrylicpaint modified with TiO2 and clay nanoparticles. Progr Org. Coat. 2013, 76, 1543-1548. [CrossRef]

24. Varga, D.; Tolvaj, L.; Molnar, Z.s.; Pasztory, Z. Leaching effect of water on photodegraded hardwood species monitored by IR spectroscopy. Wood Sci. Technol. 2020, 54, 1407-1421. [CrossRef]

25. Pasztory, Z.; Tolvaj, L.; Varga, D. Effect of water leaching on photodegraded poplar wood monitored by IR spectroscopy. Wood Res. 2020, 65, 885-894. [CrossRef]

26. Bejo, L.; Tolvaj, L.; Kannar, A.; Preklet, E. Effect of water leaching on photodegraded spruce wood monitored by IR spectroscopy. J. Photochem. Photobiol. A Chem. 2019, 382, 111948. [CrossRef]

27. Colom, X.; Carrillo, F.; Nogues, F.; Garriga, P. Structural analysis of photodegraded wood by means of FTIR spectroscopy. Polym. Degrad. Stab. 2003, 80, 543-549. [CrossRef]

28. Li, H.; Lei, X.; Wu, Y.; Hongchang, L.; Gou, X.; Wen, R.; Hu, Y. Study of the discoloration behaviour of teak wood (tectona grandis linn. fil.) caused by simulated sunlight. Wood Res. 2019, 64, 625-636.

29. Chang, T.C.; Lin, H.Y.; Wang, S.Y.; Chang, S.T. Study on inhibition mechanisms of light-induced wood radicals by Acacia confusa heartwood extracts. Polym. Degrad. Stab. 2014, 105, 42-47. [CrossRef]

30. Yu, H.; Yu, W.; Yang, L.; Fang, C.; Xu, M. Surface Discoloration Analysis and Lignin Degradation Fragments Identification of UV-Irradiated Moso Bamboo (Phyllostachys pubescens Mazel). BioRes 2015, 10, 1617-1626. [CrossRef]

31. Mattonai, M.; Watanabe, A.; Shiono, A.; Ribechini, E. Degradation of wood by UV light: A study by EGA-MS and Py-GC/MS with on line irradiation system. J. Anal. Appl. Pyrol. 2019, 139, 224-232. [CrossRef]

32. Lanzalunga, O.; Bietti, M. Photo- and radiation chemical induced degradation of lignin model compounds. J. Photochem. Photobiol. B Biol. 2000, 56, 85-108. [CrossRef] 
33. Tolvaj, L.; Mitsui, K.; Varga, D. Validity limits of Kubelka-Munk theory for DRIFT spectra of photodegraded solid wood. Wood Sci. Technol. 2011, 45, 135-146. [CrossRef]

34. Preklet, E.; Tolvaj, L.; Tsuchikawa, S.; Varga, D. Photodegradation properties of earlywood and latewood spruce timber surfaces. Acta Silv. Lignaria Hung. 2021, 17, 9-21. [CrossRef] 